\title{
CHARACTERISTICS OF BREAD AND BISCUIT MADE WITH WHEAT AND RICE FLOUR COMPOSITES
}

\section{Ivan Švec, Marie Hrušková ${ }^{1}$}

${ }^{\prime}$ Dept. of Carbohydrates and Cereals, ICT Prague, Technická, Prague, Czech Republic

\begin{abstract}
Technological quality changes of wheat flour were studied in relation to its partial replacement (5, 10, 15, 20, 25 or 30\%) by white rice flour (RF). In dependence on level added, RF lowered water absorption up to about 10\%. Dough stability was multiplied reversely as well as its overmixing tolerance - softening degree of dough lessened from 60 Brabender units (BU) for wheat flour to $20 \mathrm{BU}$ for wheat-rice flour blend 70:30. Baking quality of flour composites was worsened owing to changes in dough elasticity and extensibility (i.e. dough machinability), summarised by extensigraph energy (as an area under curve) decrease from $140 \mathrm{~cm} 2$ to $70 \mathrm{~cm} 2$ comparing the same samples. Gelatinisation temperatures and amylograph maxima reversely increased - optimal values were recorded for wheat:rice composite 80:20 yet (viscosity between 575 - 790 BU). Fermentation process was affected equivocally - gases volumes had increased up to about $11 \%$ because of glucosidase present in RF, but dough volumes lowered due to gluten net weakening. It resulted into lowering of control bread volume to a halffor the bread containing $30 \%$ of $R F$ (from 319 to $154 \mathrm{ml} / 100 \mathrm{~g}$, respectively). Bread crumb chewiness was affected seriously; bread samples higher level of RF than 20\% were less acceptable (fall of crumb penetration from $10.6 \mathrm{~mm}$ to $2.2 \mathrm{~mm}$ ). Quality changes of biscuits containing RF were of smaller extent - the substitution of 5\% caused specific volume increase about ca 15\% (from 143 to $203 \mathrm{ml} / 100 \mathrm{~g}$ ). Sizes of other fortified biscuits were gradually diminished to level of the wheat control ones.
\end{abstract}

Keywords: Wheat and rice flour, Flour composite, Viscoelastic behaviour, Fermented dough, Baking test, Bread and biscuit quality.

\section{Contribution/ Originality}

This study documents white rice flour effect on chemical composition and rheological behaviour of wheat flour. Within Europe, laboratory prepared wheat-rice bread and biscuits represent innovation in bakery products manufacturing. Study brings knowledge of $15 \%$ and $10 \%$ of rice flour in bread and biscuits recipe should be accepted by consumers. 


\section{INTRODUCTION}

Rice (Oryza sativa L.) belongs among important cereal crop and it is staple food of about three billion people around the world. The content of protein, starch, fat, minerals and vitamins, especially $\mathrm{E}$ and B, depends on genetic diversity (Noomhorm et al., 1994; Goffman et al., 2003). To prepare rice bread of the European type, absence of gluten in rice flour could be compensated by using of blends with wheat flour. Anyway, manufacturing of such bread poses a technological challenge; as was reported earlier, rice addition has an inferior impact on wheat flour rheological properties. The flour mixture shows less water absorption, a longer development time, a higher degree of dough softening and a higher gelatinization temperature compared to wheat flour (Lee et al., 1979; Nicolic et al., 2008; Sabanis and Tzia, 2009) evaluated the effect of rice addition on wheat and durum flour dough. The durum flour can be substituted with non-gluten components up to $10 \%$ more because of its stronger gluten matrix. Extensigraph data of wheat-rice dough shows considerable drop in extensibility (Seyam and Kidman, 1977). Contrary, raw rice flour caused an early increase in $\mathrm{CO}_{2}$ production during dough fermentation due to maltose hydrolysis by presented alpha-glucosidase (Takano et al., 1980). Although dough rheological behaviour indicates that rice weakened the dough, bread of acceptable quality and standard taste can be obtained depending on the level addition (Reyes-Aguilar et al., 2004). Rice flours with new characteristics were sought among the various kinds of rice cultivars (purple waxy, high-amylose, sugary) to blend with the wheat flour for the bread preparation. Nakamura et al. (2009) found the bread from the combination of wheat and new sorts of rice flour (from $30 \%$ to $40 \%$ in recipe) showed higher specific volume compared with the traditional wheat/rice bread (Takano, 1984).

Nowadays, interest of consumers is more focused to bakery cereal products as richer in their nutritional value, so in ones prepared by usage non-traditional components. Within Asian population, relevance of rice consummation in forms of mill products as well as manufacturing of cereal-based products is growing continually, and the work supports this trend. Besides worldapproved rheological test (farinograph, amylograph), the paper brings a view on rheological behaviour of fermented dough during three technological phases of bread production. Tested dough leavening, proofing and the first phase of baking in laboratory condition simulate standard bakery technology. Technological quality of wheat-rice flour blends in six variants (rice flour dosages $5,10,15,20,25$ or $30 \%$ ) was examined by the rheological proofs describing nonfermented and fermented dough characteristics. Appointed baking test of fermented bread and biscuits should reveal out consumer's value of wheat/rice composites flour, thus estimate a practical usage of the blends. 


\section{MATERIALS AND METHODS}

\subsection{Materials}

Sample of white wheat flour (W) was acquired from industrial mill in Prague, which process winter wheat planted within the Central Bohemia region. Its ash and protein contents were $0.64 \%$ and $11.3 \%$, respectively, determined by using of commercial infrared spectrometer Nicolet 8600 (Perten Instruments, Sweden; calibration follows the ČSN 560512 method). According to the Zeleny test (ČSN ISO 5529), determined protein quality was $40 \mathrm{ml}$. Amylase activity estimated as the Falling Number (ČSN ISO 3039) was assessed on level 365 s, i.e. about 100 units higher than empirical optimum $(250 \pm 25 \mathrm{~s})$.

White rice flour (RF) produced by Paleta Ltd. (Lipnice, Czech Republic) was bought in a specialised shop. Ash and protein contents were lower compared to W sample (0.57\% and $7.3 \%$, respectively).

Wheat-rice flour composites of amount $300 \mathrm{~g}$ were prepared in ratios 95:5, 90:10, 85:15, 80:20, 75:25 and 70:30 (w/w), respectively, and were coded WRF5 - WRF30, respectively.

Rheological procedures and baking test were performed with control sample $\mathrm{W}$ and all six wheat-rice composites WRF5 - WRF30.

\subsection{Flour, Dough and Bakery Product Quality Evaluation}

Rheological behaviour of $\mathrm{W}$ and blends were evaluated with the help of the farinograph and the extensigraph (Brabender, Germany), following ISO 5530-1 and ISO 5530-2 procedures (nonfermented dough properties during kneading and uniaxial deformation, respectively). Viscous properties of samples were determined by using of the amylograph (Brabender, Germany) according to ICC 126/1 method (registration of viscosity of water-flour suspension during heating from $25^{\circ} \mathrm{C}$ to $100{ }^{\circ} \mathrm{C}$ ). To cover rheological behaviour of dough during three technological steps of fermentation process (leavening, proofing and the first phase of baking), the fermentograph, the maturograph and the oven rise proofs, respectively, were carried out according to the internal methods. The first two methods are performed within chambers tempered to $30^{\circ} \mathrm{C}$ and relative humidity of $95 \%$, the oven rise one in an oil bath heated from $25^{\circ} \mathrm{C}$ to $100{ }^{\circ} \mathrm{C}$ in 22 minutes. The fermentograph record allows an evaluation of optimal fermentation time (a period to the first recognizable gases escape from dough) and final volumes of both fermentation gases and dough in approximately 3 hours of duration. After approximately one hour of the test, when dough sample is periodically weighted down each 2 minutes, the maturograph zig-zag curve is characterised by optimal proofing time (time to reaching of dough maximal volume), dough resistance (i.e. maximal volume), dough elasticity and stability (of the maximal volume). The paper readings of the oven rise proof comprises data of mass change of standardly leavened and proofed dough piece - volumes at the test beginning, one in 11 th minute of the test, and final bread volume (in 22 nd minute); also total volume increase is evaluated. 
Preparing hand-made buns from fermented dough as well as biscuits fluffed up by baking powder, RF influence on bakery product quality was determined following the internal methods. By using of the farinograph, both dough types were prepared to consistency 600 Brabender's units (BU), adding the same amount of water (water absorption $58.0 \%$ on $300 \mathrm{~g}$ flour base). Bread manufacturing was describer earlier (Švec et al., 2004), a basic recipe comprises $300 \mathrm{~g}$ flour (or composite flour), $12.0 \mathrm{~g}$ compressed yeast, $5.1 \mathrm{~g}$ salt, $4.5 \mathrm{~g}$ sugar and $3.0 \mathrm{~g}$ table margarine $(80 \%$ of fat) and distilled water. Optimally leavened and proofed dough (50 and $45 \mathrm{~min}$, respectively; $30{ }^{\circ} \mathrm{C}$, RH 95\%) was divided into pieces of $70 \mathrm{~g}$, which were moulded by hand and baked on plate with steaming for $14 \mathrm{~min}$ at $240{ }^{\circ} \mathrm{C}$. Evaluated bread quality features include specific bread volume $(\mathrm{BrV})$, shape ratio of bread (height-to-diameter ratio, $\mathrm{BrS}$ ) and 9-point sensorial profile (e.g. bread vaulting crust colour and brightness, crust crispiness, crumb porosity, bread aroma and taste) in scale of 9 to 27 points (the best and unacceptable bread, respectively). By using of the penetrometer PNR-10 (Petrotest Instrument, Germany), bread consumer quality was determined as crumb penetration rate (PEN), corresponding to crumb firmness or chewiness.

Biscuits were prepared according to basic formula: $300 \mathrm{~g}$ wheat flour or wheat-rice composite, $30 \mathrm{~g}$ sugar, $10 \mathrm{~g}$ sunflower oil, $6 \mathrm{~g}$ baking powder $\left(\mathrm{NaHCO}_{3}\right), 1.8 \mathrm{~g}$ salt, $0.15 \mathrm{~g}$ ascorbic acid and distilled water. After resting of 30 min into fermentation chamber $\left(30{ }^{\circ} \mathrm{C}, \mathrm{RH}\right.$ $95 \%$ ), dough mass split into halves was handled by a rolling pin onto special desk ensuring dough plate height of $5 \mathrm{~mm}$. Biscuits were cut out by circle metal sheet with diameter of $55 \mathrm{~mm}$, and placed onto baking plate. Baking 15 min long was performed without steaming into laboratory oven preheated to $180^{\circ} \mathrm{C}$. Baked biscuits characteristics were examined after 10 min of cooling at a room temperature. Biscuit height-to-diameter ratio (BiS) was evaluated by a slide ruler, and also their volume $(\mathrm{BiV})$ by rapeseed displacement method was assessed (repeatability 0.045 and 6.5 $\mathrm{ml} / 100 \mathrm{~g}$, respectively). By sensorial analysis in a hedonic scale, biscuit colour, aroma and taste were categorised as "typical, satisfying" or "other, strange" with detailed word description of character of potential by-taste.

\section{RESULTS AND DISCUSSION}

\subsection{Rheological Behaviour of Non-Fermented Dough}

Compared to results published by Nicolić et al. (2008) farinograph, extensigraph as well as amylograph tests shown similar tendencies. For composite WRF30, a decrease about 6 units in water absorption was determined. Also dough stability was prolonged approximately three-times as a result of slower water absorption by rice starch granules. In comparison of dough softening degrees of W and WRF30 only, sample of Czech wheat flour was influenced somewhat strongly (from $60 \mathrm{BU}$ to $20 \mathrm{BU}$, respectively) than the Serbian one (from $40 \mathrm{BU}$ to $20 \mathrm{BU}$, respectively).

Extensigraph data confirmed good baking quality of control sample W. Dough energy was $140 \cdot \mathrm{cm}^{2}$ and calculated elasticity-to-extensibility ratio was 2.6 (data corresponding to good dough 
machinability). Addition of $30 \%$ of RF caused both energy and ratio diminishing to $70 \mathrm{~cm}^{2}$ and 2.8, respectively. Such change extent observed also Nicolić et al. (2008) - energy fell from $101 \cdot \mathrm{cm}^{2}$ to $52 \cdot \mathrm{cm}^{2}$; the ratios of 2.57 and 2.33 , respectively, could be considered also as comparable. The tendency was confirmed also by Sabanis and Tzia (2009) - 30\% of RF lowered extensigraph extensibility to $74 \%$ and energy to $50 \%$ in relation to wheat control. For the tested samples W and WRF30, determined diminishing was comparable (77\% and 44\%, respectively).

Pasting properties of $\mathrm{W}$ and WRF30 differed in both gelatinisation temperature and in suspension maximal viscosity. The former parameter increased about 5 units (from $88{ }^{\circ} \mathrm{C}$ to $93{ }^{\circ} \mathrm{C}$ ), while the latter has been multiplied twice (from 575 to $1000 \mathrm{BU}$ ). For samples of the identical composition, Nicolić et al. (2008) found similar peak temperatures $\left(88^{\circ} \mathrm{C}\right.$ and $98{ }^{\circ} \mathrm{C}$, respectively), but viscosity rise was lower (480 BU and $790 \mathrm{BU}$ ).

\subsection{Rheological Behaviour of Fermented Dough}

Relationship between the first and the second phase of fermentation (fermentograph dough volume, gases volume vs. maturograph dough resistance, respectively) is illustrated in Fig. 1. Only the volume of fermentation gases has risen, supported both by introduced alpha-glucosidase and by smaller rice starch particles better accessible to enzymes action (Takano et al., 1980). Within the tested set, gas volume parameter could not be used for tested samples differentiating. Due to gluten matrix weakening by RF portions applied, both the fermentograph dough volume and the maturograph dough resistance have fallen about $30 \%$ in total. For the maturograph resistance, the lowest $\mathrm{RF}$ addition did not caused noticeable dough weakening although extensigraph elasticity of that dough decreased significantly. Different behaviour during maturograph test corresponds to full-formula-dough including fat, which supports gases capture. According to the recorded values, sample pairs W-WRF5 and WRF25-WRF30 could be considered as statistically diverse in both the fermentograph dough volume and the maturograph resistance.

Behaviour of fermented dough piece in an oil bath agreed with the fermentograph and the maturograph data, i.e. bread volume was markedly affected by RF addition. Difference between the control and the most fortified dough was also approximately $30 \%$ (545 and $380 \mathrm{BU}$, respectively; Fig. 2), and such difference is verifiable.

\subsection{Bread Quality}

Similarly to the farinograph proof, the higher ratio of $\mathrm{RF}$ in a full-formula-dough, the less amount of water was necessary to prepare bread dough of demanded consistency. Water absorption was lowered in a higher extent by using of $80 \%$ margarine compared to oil applied in biscuit recipe (Table 1a and 1b, respectively). Regardless to that, a dominant role is attributed to flour part of composites - a stepwise decrease was nearly $1 \%$ in both cases. 
Volumes of control and WRF5 composite bread could be considered as comparable with respect to measurement repeatability. Sizes of composite bread richer in RF were affected seriously (diminishing approximately about 51\%), but differences between WRF20, WRF25 and WRF30 bread samples were found to be non-significant (Table 1a). Within the tested set, BrS values were statistically indifferent - it ranged from 0.60 to 0.52 (W vs. WRF5 and WRF30, respectively; Table 1a).

Measured PEN values corresponded with oven rise bread volume well (Fig. 2). Verifiable differences were found between samples W-WRF5, WRF 10-WRF 15 and WRF30. However, the PEN lower than 5-7 mm represents very firm crumb, unacceptable by consumers. Sensory profiles of enhanced bread were worsened by higher RF ratio in recipe, too - proportion of visually noticeable rough crust and a rate of sandy/chalky taste increased. Quantified, standard and WRF5-WRF10 bread reached common quality (11-12 points at minimum of 9). Further, WRF 15 and WRF20 bread had a somewhat worse score (14 and 17 points, respectively), while profile of WRF25 and WRF30 ones approach to bread of unacceptable quality (20 and 21 points; maximum of 27$)$.

Lee et al. (1979) reported the $\mathrm{BrV}$ decrease from $780 \mathrm{~cm}^{3}$ (control wheat bread) to 720,685 and $650 \mathrm{~cm}^{3}$ for wheat-rice composites of 90:10, $80: 30$ and 70:30 (w/w) (i.e. diminishing about $8 \%$, $12 \%$ and $17 \%$, respectively). Total sensorial score of these bread samples have been worsened about $5 \%, 14 \%$ and $25 \%$, respectively. However, Nakamura et al. (2009) valued as still acceptable bread prepared from wheat-rice composites 70:30 and 60:40, respectively.

\subsection{Biscuit Quality}

Biscuit recipe enhancement by RF was reflected in product size similarly to bread. Biscuit volumes containing WRF5 or WRF25 and WRF30 were verifiably distinguished from the others (Table 1b). Considering the BiV repeatability, all differences were provable slightly. The BiS was partially improved by all tested RF additions, but observed differences were insignificant.

Biscuit colour was in all cases defined as typical, light beige tint, so effect increasing $\mathrm{RF}$ portion in biscuits was not proved. Taste of biscuits up to $10 \%$ of the RF was typical and adequate for that type of biscuits. Baking powder taste could be identified in the other tested samples (WRF15-WRF30), which has increased to nearly unpleasant intensity. Reason for this could be an incomplete activity of $\mathrm{NaHCO}_{3}$, which led to lower biscuit volumes, too. There is a similarity to bread profile determination - consumer's quality of WRF 15 and others composite bread was provably worse than one of bread prepared according to standard formula (pure wheat) and with WRF 5 or WRF 10 flour composites. 


\section{CONCLUSIONS}

White rice flour affected dough machinability by protein elasticity increase and extensibility diminishing. It resulted into bread volume lowering as well as crumb hardening without effect on buns vaulting. Sandy by-taste was tolerable to $15 \%$ of rice flour. Prepared biscuits have acceptable overall quality up to $10 \%$ of rice flour only.

\section{REFERENCES}

Goffman, F., S. Pinson and C. Bergman, 2003. Genetic diversity for lipid content and fatty acid profile in rice brain. Journal of Agricultural and Food Chemistry, 80(5): 485-490.

Lee, C.Y., S.K. Kim and P.E. Marston, 1979. Rheological and baking studies of rice-wheat flour blends. Korean Journal of Food Science and Technology, $11(2):$ 99-104.

Nakamura, S., K. Suzuki and K. Ohtsubo, 2009. Characteristics of bread prepared from wheat flours blended with various kinds of newly developed rice flours. Journal of Food Science, 74(3): 121-130.

Nicolić, N., N. Radulović, B. Momcilović, G. Nikolić, M. Lazić and Z. Todorović, 2008. Fatty acids composition and rheology properties of wheat and wheat and white or brown rice flour mixture. European Food Research and Technology, 227(5): 1543-1548.

Noomhorm, A., D.C. Bandola and N. Kongseree, 1994. Effect of rice variety, rice flour concentration and enzyme levels on composite bread quality. Journal of the Science of Food and Agriculture, 64(4): 433-440.

Reyes-Aguilar, M.J., P. Palomo and R. Bressani, 2004. Development of bakery products for greater adult consumption based on wheat and rice flour. Achivos Latinoamericanos de Nutricion, 54(3): 314321.

Sabanis, D. and C. Tzia, 2009. Effect of rice, corn and soy flour addition on characteristics of bread produced from different wheat cultivars. Food and Bioprocess Technology, 2(1): 68-79.

Seyam, A.M. and F.C. Kidman, 1977. Rheological properties and bread quality of wheat and rice starch composite flours. Staerke, 28(6): 216-220.

Švec, I., M. Hrušková, J. Blažek and O. Jirsa, 2004. Baking parameters of wheat variety from international breeding test. Getreidetechnologie, 58(3): 145-151.

Takano, H., 1984. Development of novel processed rice products. Report of Research Project of Research Council of Agriculture, Forestry and Fisheries, Japan, No. 161. pp: 117-130.

Takano, H., Y. Koyanagi and Y. Takana, 1980. Bread making properties of rice flour. II. On the fermentation properties of wheat flour-yeast dough mixed with rice flour and its change in sugar content during fermentation. Journal of the Japanese Society for Food Science and Technology, 27(10): 522-528. 
Table-1. ANOVA of white rice effect on bakery product parameters

\begin{tabular}{|c|c|c|c|c|c|}
\hline A. Bread & & & & & \\
\hline \multirow[t]{2}{*}{ Sample } & Water addition (\%) & \multirow{2}{*}{$\begin{array}{l}\mathrm{BrV}(\mathrm{ml} / 100 \mathrm{~g}) \\
\text { Mean }\end{array}$} & \multirow[b]{2}{*}{ SD } & \multirow{2}{*}{$\begin{array}{l}\text { BrS (1) } \\
\text { Mean }\end{array}$} & \multirow[b]{2}{*}{$\mathrm{SD}$} \\
\hline & & & & & \\
\hline $\mathrm{W}$ & 58.0 & $319 \mathrm{e}$ & 3 & $0.60 \mathrm{a}$ & 0.02 \\
\hline WRF5 & 56.5 & $315 \mathrm{e}$ & 9 & $0.60 \mathrm{a}$ & 0.02 \\
\hline WRF 10 & 55.5 & $258 \mathrm{~d}$ & 11 & $0.57 \mathrm{a}$ & 0.03 \\
\hline WRF 15 & 54.4 & $203 c$ & 8 & $0.57 \mathrm{a}$ & 0.00 \\
\hline WRF2O & 53.3 & $174 \mathrm{bc}$ & 21 & $0.54 \mathrm{a}$ & 0.07 \\
\hline WRF25 & 52.2 & $139 \mathrm{a}$ & 4 & $0.60 \mathrm{a}$ & 0.01 \\
\hline WRF30 & 51.0 & $154 \mathrm{ab}$ & 5 & $0.52 \mathrm{a}$ & 0.00 \\
\hline \multicolumn{6}{|c|}{ B. Biscuit quality } \\
\hline \multirow[t]{2}{*}{ Sample } & Water addition (\%) & \multirow{2}{*}{$\begin{array}{l}\mathrm{BiV}(\mathrm{ml} / 100 \mathrm{~g}) \\
\text { Mean }\end{array}$} & \multirow[b]{2}{*}{ SD } & \multirow{2}{*}{$\begin{array}{l}\text { BiS (1) } \\
\text { Mean }\end{array}$} & \multirow[b]{2}{*}{$\mathrm{SD}$} \\
\hline & & & & & \\
\hline $\mathrm{W}$ & 58.0 & $177 \mathrm{~b}$ & 10.4 & $0.27 \mathrm{a}$ & 0.01 \\
\hline WRF5 & 58.5 & $203 c$ & 2.4 & $0.35 \mathrm{a}$ & 0.04 \\
\hline WRF10 & 57.3 & $152 \mathrm{ab}$ & 1.5 & $0.34 \mathrm{a}$ & 0.03 \\
\hline WRF 15 & 56.0 & $157 \mathrm{ab}$ & 1.0 & $0.30 \mathrm{a}$ & 0.04 \\
\hline WRF2O & 55.0 & $152 \mathrm{ab}$ & 4.3 & $0.31 \mathrm{a}$ & 0.04 \\
\hline WRF25 & 54.5 & $150 a$ & 4.3 & $0.37 \mathrm{a}$ & 0.04 \\
\hline WRF30 & 52.0 & $145 \mathrm{a}$ & 1.2 & $0.33 a$ & 0.05 \\
\hline
\end{tabular}

BrV: specific bread volume, BrS: bread shape ratio.

BiV: specific biscuit volume, BrS: biscuit shape ratio; SD: standard deviation.

W: wheat flour, WRF 5 -WRF30: wheat-white rice flour composites with $5-30 \%$ of rice flour.

a, b-Column means signed by the same letter are not statistically different $(\mathrm{P}=95 \%)$. 